\title{
CURSOS UNIVERSITÁRIOS \\ PROBLEMAS DO ENSINO MÉDICO
}

\author{
Milton Munhoz \\ Professor da Faculdade de Medicina da \\ Universidade do Paraná
}

Em 1912, o advento da Universidade do Paraná veio dar corpo e sentido à conquista política de 1853, traçando as coordenadas do nosso futuro, robustecendo a nossa consciência de liberdade e independência e mostrando precocemente a nossa destinação histórica de criar no Paraná uma civilização alicerçada também em sólidos fundamentos da cultura filosófica e científica.

Está bem viva na memória do Paraná e do Brasil a estupenda realização daqueles idealistas de porte heróico.

Nascida de um sonho e acalentada pelo ideal, os seu fundadores pouco mais lhe poderiam dar além da sua obstinação, da sua tenacidade e da sua determinação em fazê-la vingar de qualquer modo.

Improvisou-se românticamente uma Universidade, que atingiu, finalmente, por esforço próprio, até onde poderia chegar empreendimento particular dessa natureza.

Adotada pela União, ela é hoje uma das grandes Universidades brasileiras.

Mas não está perfeita. Há ainda muito o que fazer.

Os tempos mudaram. As exigências do ensino cresceram. 
A ciência deu saltos gigantescos. Transformou-se profundamente o panorama político-social do mundo. Os bons tempos descuidados passaram. Reclama-se das Universidades maior esforço para defesa da civilização.

Um organismo de tal envergadura já não póde apoiar-se sòmente na trađiçãa idealística dos primeiros dias. As contingências atuais exigem-lhe atuação firme e objetiva. A complexidade de sua missão social impõe-lhe obrigações realísticas, concisas e bem definidas. A sua estruturação reclama recursos humanos e materiais de primeira qualidade e já não lhe bastam os impulsos generosos e as dedicações amorosas e idílicas do noviciado.

Se a Universidade tem por fim elaborar, ensinar e divulgar as ciências, além de estimular na comunidade estudantil os seus impulsos de gregarismo humano, "nada de imutável diz o Prof. Fernando Azevedo - deve nela existir, nada de fixo, de parado, nada que seja suscetível de constranger a sua evolução ou de submetê-la a padrões rígidos que possam entravar-lhe o desenvolvimento ou o processo normal de adaptação às condições do tempo e os quadros geográficos e culturais do país".

Mas há que respeitar a tradição de suas finalidades, mantendo em equilíbrio, tanto quanto possível, as suas fontes fundamentais de poder.

O Prof. James Bryant Conan, Presidente da Universidade de Harvard, insiste no respeito aos princípios basilares que procedem das universidades europeias dos séculos XVII e XVIII quando afirma que "o cultivo da ciência por si só não produz uma Universidade mas um Instituto de Investigação; a preocupação exclusiva pela vida estudantil um country club ou uma equipe de futebol; a educação profissional por si mesma produz uma escola comercial; e a educação geral divorciada da investigação e da preparação para as profissões liberais não é, sem dúvida, uma Universidade e sim um Colégio".

No Brasil, mais que em qualquer outro país, o papel das Universidades tem ainda que se estender aos estudos dos nos- 
sos problemas e à formação das elites dirigentes. Devemos enquadrá-las na conceituação de Raimundo Poincaré, para quem uma Universidade deve ser, no conjunto, escola universal, escola nacional e escola regional.

Afirmou em memorável sessão dà Assembléia Universitária o Magnífico Reitor, Prof. Flávio Lacerda, que a Universidade do Paraná, "há de sacudir conceitos caducos e quer ter a primazia de inaugurar no Brasil o regime universitário orgânico e integral".

Estamos, pois, no caminho certo e confiamos que a diretriz tão corajosamente esposada nos conduza a situação previlegiada e nos preserve daquelas crises, denunciadas por Ortega y Gasset e Benedito Croce, que avassalaram as universidades europeias modernas, seja pelo predomínio da investigação ou pela exclusividade da formação profissional ou ainda pelo retorno puro e simples ao eruditismo divorciado das reais necessidades do momento.

A preocupação dominante na Faculdade de Medicina é de ajustar o seu ensino dentro de normas modernas seguras e compatíveis com a realidade brasileira e de conformidade com a 0 rientação atual da Reitoria da Universidade.

Representada nos últimos Congressos em que se discutiram assuntos referentes ao Ensino da Medicina Preventiva, em Vina del Mar, e a reforma do Ensino Médico no Brasil, em Ribeirão Preto, a nossa Faculdade deseja pôr em execução dentro do menor prazo possível as conclusões daqueles certames, a que concorreu com a prática e experiência de seus professores.

O ensino da Medicina não póde ser estático, e tem forçosamente que acompanhar o desenvolvimento social e econômico do país e adaptar-se aos incessantes progressos científicos. Daí a necessidade de sua revisão periódica, sob pena de tornar-se obsoleto.

Os modernos métodos de ensino universitário devem ajudar o estudante a desenvolver suas capacidades de observação, 
comparação, análise, raciocínio e dedução, que o habilitem a continuar sua educação após a saída da Escola.

O objetivo da educação médica é criar condições para que o estudante adquira conhecimentos, habilidades, atitudes e conciência ética que o capacitem, como médico, a promover, preservar e restaurar a saúde.

E como o conceito de saúde tem atualmente outro significado, devendo ser entendido como "um estado de completo bem estar físico, mental e social e não sòmente à ausência de afeções ou enferimdades", amplia-se o papel do médico na sociedade. Êle deve entender o homem como uma unidade biológica, integrado em seu meio físico, familiar e social.

Na formação do médico não podem pois estar ausentes a psicologia, a antropologia social, a ecologia, os problemas médico-sociais, da família, da comunidade e do país, as indispensáveis técnicas de educação sanitária e o conhecimento das organizações de saúde pública e assistenciais da sua localidade.

Prevenção e cura são preocupações que devem estar associadas na preparação do médico. Diagnosticar bem, tratar corretamente e prevenir sempre, eis a síntese da profissão médica.

A precedência em importância cabe à prevenção e à preservação da saúde. Daí a maior enfase que requer o ensino da $\mathrm{Me}-$ dicina Preventiva, que deve ser feito durante tôda a duração do curso, integrada nas demais cadeiras e totalisada depois em uma

O que se pretende com isso é que todos os médicos, qualquer que seja a sua especialidade, estejam em condições de cooperar para a prevenção e a preservação da saúde individual afim de que a saúde coletiva fique resguardada, isto é, que todos os médicos possuam uma consciência preventiva.

No Brasil, em virtude de condições especialíssimas do nosso território e das nossas populações, esta mentalidade médica é fundamental. 
Contando com apenas 40 médicos por 100.000 habitantes, mal distribuidos, em que a relação no interior é muito baixa, de 16,4 por 100.000 e com $23 \%$ dos municípios sem médico, a situação médico-assistencial do Brasil é calamitosa e só comparável com a dos países sub-desenvolvidos.

A desproporção entre o número de médicos e a população cria um problema sério no Brasil. Em média, temos 1 médico para 2.500 habitantes, quando a relação ideal é de um para mil. Nos Estados Unidos há um médico para 777 habitantes e no Canadá um para 989.

Para atender as nossas necessidades no terreno médico-social, novas Escolas de Medicina estão surgindo no Brasil.

A atual legislação estipula condições mínimas para o funcionamento das novas escolas, mas essas exigências vem sendo agora julgadas insuficientes, pensando-se em torná-las mais rigorosas e categóricas.

O ensino da medicina só pode ser feito em grandes centros, em Escolas que possuam corpo docente habilitado, instalações completas para as disciplinas do currículo, hospitais com serviços indispensáveis e número de leitos suficiente para o ensino normal e o internato e amplos recursos financeiros para a sua manutenção.

Com a limitação de matrículas de acôrdo com a capacidade didática da Escola, que é condição fundamental para o bom ensino, não pode o Brasil, no ritmo atual, cobrir o déficit existente em seu número de médicos.

As nossas Faculdades diplomam sòmente cerca de 1.250 médicos por ano, quando na realidade precisamos de muito mais.

Só há dois caminhos a seguir: - ampliação das grandes Faculdades oficiais ou permissão para que se instalem em regiões geográficas apropriadas novas e boas escolas, pois, antes da quantidade deve prevalecer a qualidade dos diplomados. 
Para melhorar o ensino médico no Brasil qualquer reforma que se pretenda terá também que estimular a investigação científica, por ser ela indispensável ao progresso da Medicina, sendo elemento essencial para a formação dos futuros docentes.

Falta-nos o verdadeiro espírito científico, não há atmosfera científica em nossos cursos universitários e só a prática contínua da investigação, mesmo em trabalhos diários de rotina, poderá criá-la.

O saudoso Professor André Dreyfus atribuia o fracasso brasileiro na pesquiza à falta de orientação idônea, à raridade de contátos culturais, à ausência de instrumentos de investigação, à pobresa bibliográfica, à escassa remuneração e, sobretudo, à defeituosa seleção do elemento humano.

Um dos fatores de êxito do ensino universitário em geral e da Medicina em particular reside nos contátos constantes entre professores e alunos, só possível no recesso de laboratórios de trabalho.

0 professor tem que se dedicar integralmente ao magistério e concentrar tôdas as suas atenções à função docente.

O regime de tempo integral ou dedicação exclusiva, mais conhecido como "full-time", permite ao professor mais amplo desenvolvimento do programa, realisação de seminários, discussões bibliográficas, trabalhos pessoais em laboratórios, clínicas, ambulatórios e no meio social.

Êsse regime, reclamado agora para as Faculdades de Medicina, deve, em rigor, atingir a tôdas escolas universitárias.

Nos Estados Unidos, segundo depoimento do Prof. Almeida Jor., até nas Faculdades de Direito é êle observado.

Instituído nos cursos médicos, desde logo, para as cadeiras básicas e gradativamente para as outras disciplinas, êle deve ser atribuído, na fase de transição, antes ao indivíduo que ao cargo. 
Às Escolas Universitárias compete preparar o seu pessoal docente, afim de evitar o auto-didatismo, que infelizmente ainda viceja no Brasil, e, com a vigência dêsse regime, será mais fácil descobrir e amparar as verdadeiras vocações para o magistério.

Conveniente formação dos quadros docentes só pode ser obtida aproveitando-se, com critério, os auxiliares de ensino comprovadamente eficientes e promovendo-os, à base de merecimento, aos graus mais elevados da carreira até a conquista, por concurso, da cátedra.

$\mathrm{Na}$ atual legislação do ensino superior já está prevista a carreira úniversitária, necessitando apenas certas alterações no sentido de estabelecer correlações entre os títulos e os cargos, afim de impedir que elementos estranhos aos seus escalões possam a vir ocupar postos, prejudicando o acesso dos que estão nos seus primeiros degraus.

De outro lado, o nosso atual currículo médico é considerado inadequado em virtude de muitas falhas, tais como: falta de entrosamento entre as cátedras com omissões descabidas ou então repetições inúteis nos programas; falta de unidade no ensino decorrente da multiplicidade de cátedras; atrofia de uns e hipertrofia de outros setores de ensino; excesso de desenvolvimento nas cátedras especializadas; ausência quasi completa de ensino em ambulatórios e completa no ambiente domiciliar.

As correções preconisadas são: prelecionamento das matérias em 5 anos, utilisando-se o sexto para o internato hospitalar obrigatório; melhor aproveitamento dos períodos letivos; supressão das provas parciais; redução do número de horas dedicadas ao ensino das especialidades; alteração da seriação das cadeiras, diminuição do número destas e criação dos Departamentos.

A organização departamental é, em rigor, a reunião de várias disciplinas afins sob uma única supervisão, mas no caso concreto do Brasil poderia ser a reunião de várias cátedras, cabendo a direção a um dos professores. 
Com os departamentos haverá unidade de ensino, economia de tempo, de pessoal e de material e seriam evitadas as repetições e afastadas as omissões nos programas.

O internato obrigatório em hospitais para os alunos do $6 .^{\circ}$ ano, sem outras obrigações escolares, será de real conveniência e deve ser instituído desde já, em forma rotativa, durante 12 meses consecutivos, nos serviços de clínicas médica, cirúrgica, obstétrica e pediátrica, no mínimo.

Cogita-se também da instituição da residência, que é uma etapa necessária à especialisação, sendo um recurso facultativo para aquêles que, depois de formados, desejarem obter e aprofundar conhecimentos em determinado ponto médico.

É imprescindível que as Universidades selecionem melhor os candidatos que se apresentam em número sempre crescente aos exames vestibulares.

Atualmente, só se leva em conta a prova de conhecimentos informativos, não se cogitando das qualidades morais e nem das aptidões garantidoras de aproveitamento no curso, despresando-se por completo a prova de capacidade intelectual dos candidatos.

Como um filtro capaz de permitir melhor seleção, pensa-se em restabelecer os cursos pré-universitários, de um ano de duração, com número de matrículas limitado e igual número de vagas no primeiro ano do curso respectivo.

Nesse ano, verdadeiro traço de união entre o secundário e o superior, seriam os alunos observados e classificados pelas suas qualidades intelectuais, morais e de escolaridade, passando automàticamente à Faculdade os aprovados e procedendo-se o concurso vestibular para o preenchimento de vagas restantes.

Se não fôr êsse mecanismo a adotar, qualquer outro que o substitua deverá permitir um critério justo de seleção.

O elemento humano é o fator mais importante de uma Uni- 
versidade, A razão está em Gilman, da Universidade de John Hopkins, quando diz que "a glória das universidades deve repousar no caráter de mestres e estudantes".

Como órgão de ensino e de cooperação social, ìntimamente ligada à comunidade, aos poderes públicos, às instituições privadas e aos centros culturais, tem a Universidade que estar presente pelos seus mais credenciados representantes, em todos os movimentos do saber, da política, das transformações sociais, da ascenção espiritual e moral do homem, intervindo com autoridade e respeito, sabedoria e inteligência, moralidade e honestidade para solução de questões de transcendente importância para o bem estar do meio e da humanidade.

Focalisando superficialmente aspectos do ensino médico, que me é mais familiar, tudo quanto a respeito foi dito aplica-se, em essência, ao estudo universitário em geral, pois são coincidentes os seus objetivos; as falhas de um são as mesmas de outro; iguais as reivindicações defendidas; os anseios de progresso e perfeição se confundem num só desiderato: a grandeza do ensino superior do Brasil.

Trabalha-se ativamente na nossa Universidade para fazê-la maior e melhor. Graças ao descortino, à inteligência, ao patriotismo e o acendrado amor à sua terra, do ilustre Magnífico Reitor Prof. Flavio Lacerda, e de não menores predicados dos senhores Diretores das Faculdades, Professores e de todos os integrantes dos seus órgãos deliberativos, desenvolve-se entre nós um vasto programa de realizações que elevarão ainda mais alto o nome glorioso da Universidade do Paraná, patrimônio imponente do nosso povo e que temos a obrigação de engrandecer, enobrecer e defender. 